ISSN electrónico: 2172-9077

DOI: https://doi.org/10.14201/fjc202021710

\title{
Adolescentes EN SERIE. JÓvENES PROTAGONISTAS EN LA FICCIÓN TELEVISIVA
}

\section{Serialised Teens. Young Protagonists in TV Fiction}

\author{
Dra. Belén PUEBLA-MARTÍNEZ \\ Profesora Ayudante Doctor, Universidad de Rey Juan Carlos, España \\ E-mail: belen.puebla@urjc.es \\ (iD) https://orcid.org/0000-0002-1481-4238
}

\author{
Dra. Edisa MONDELO GONZÁLEZ \\ Profesora Titular, Universidad de Rey Juan Carlos, España \\ E-mail: edisa.mondelo@urjc.es \\ (iD) https://orcid.org/0000-0002-3430-6337
}

En las últimas décadas estamos asistiendo a un crecimiento exponencial de las series televisivas, tanto en cantidad (casi inabarcable) como en calidad (la televisión ya ha dejado de ser la hermana pobre del cine). "Las nuevas tecnologías han alterado de manera radical la forma de consumir televisión e, indirectamente, algunos hábitos establecidos a la hora de producirla [...] En un proceso global para todo el medio, segmentos poblacionales como los jóvenes, han dejado de consumir el indiferenciado flujo televisivo para pasar a ver únicamente programas que han captado su interés”. (Cascajosa, 2009: 28-29). La aparición y consolidación de las nuevas plataformas de producción y exhibición (Netflix, HBO, Amazon Prime...) ha transformado por completo el panorama televisivo, y uno de sus puntos fuertes han sido precisamente las series. También las televisiones generalistas parecen haber incrementado su apuesta por esta forma de narración.

Si repasamos, de forma incluso superficial, la producción de estos últimos años encontramos innumerables series de ficción, tanto en las plataformas de pago como en las televisiones generalistas, donde el o los papeles protagónicos, aun compartidos con adultos, recaen en jóvenes o adolescentes. Estas series ya no están pensadas únicamente para un público específico coincidente con esa franja de edad, ni tampoco quedan circunscritas a unos géneros determinados asociados a ese target.

Series de gran seguimiento como Strangers Things, The OA, Élite, Merlí.. abarcan muy diferentes tipos de relatos y evidentemente no están pensadas para un público exclusivamente juvenil. A partir de sagas cinematográficas tan exitosas como Crepúsculo, Los juegos del hambre, Divergente o Harry Potter, la industria ha encontrado un perfil protagónico relativamente poco explotado, dirigido a un mercado mucho más amplio y no restringido a un público fundamentalmente "adultescente». En la mayor parte de los casos, se puede considerar que si bien se huye de la fragmentación del 
público por franja de edad, si se produce esa selección/fragmentación en cuanto al tipo de relato, adscrito generalmente a los que podríamos denominar «géneros populares», implicando un perfil de público muy concreto en el caso de relatos de terror o fantasía, o más amplio, en los casos reconocibles como romántico o aventura, aunque la hibridación contemporánea hace difícil en muchos casos su adscripción a una única tipología.

La aparición de protagonistas adolescentes en diferentes roles, que en ocasiones se complementa con un proceso madurativo del personaje, es en palabras de Galán-Fajardo (2006: 65) «un recurso esencial para generalizar y reiterar atributos sobre grupos sociales contribuyendo a la creación, en el espectador, de prejuicios y opiniones predeterminadas». De mismo modo que Raya, Sánchez-Labella y Duran, 2018) señalan que «algunas series teen del siglo XXI pretenden dar una visión más realista y menos estereotipada de los adolescentes y sus procesos de maduración, conscientes de la capacidad reflexiva que permiten este tipo de ficciones». Todo ello confiere una consolidación a las series protagonizadas por adolescentes debido a una coyuntura delimitada por los factores económicos, sociales y, sobre todo, tecnológicos que se están generando en el siglo XXI (Ross \& Stein, 2008).

Viendo estas premisas nos encontramos frente a un objeto de estudio poliédrico, con numerosos enfoques que, bajo este paraguas de análisis, han conformado los siete trabajos de investigación de este monográfico. Desde diferentes perspectivas se realizan aportes significativos que van a generar espacios de debate sobre la tendencia en alza de las teen series en el panorama actual de la ficción televisiva global.

El artículo de Gelado, Poch-Butler y Moreno que abre el monográfico trata de poner en relación el contenido de la serie 13 Reasons Why, analizada a través de su primera temporada por entenderse como la más coherente con el espíritu inicial expuesto en el propio nombre (las 13 razones que llevaban a su protagonista a suicidarse), y las motivaciones que empujaron a sus creadores a alumbrar la serie, analizadas a través de los testimonios recogidos en el documental (primera temporada también) Más allá de las razones. Se ha comparado tanto la frecuencia con la que aparecen unas y otras fuentes como el contenido de su discurso, lo que ha acabado deparando disonancias evidentes entre lo que los creadores de la serie decían pretender conseguir con ella y lo que el discurso de la serie sugería.

Por su parte y desde una perspectiva que mezcla elementos cuantitativos con un análisis cualitativo-descriptivo, Ferrera ha realizado una comparación entre los personajes adolescentes de 23 series originales europeas de la plataforma Netflix de tal manera que destaca la importancia que dan estos personajes a sus grupos de pertenencia y a las cuestiones sexuales como las tramas más relevantes, y dando especial relevancia a la lectura de la ficción seriada europea original de Netflix como un gran discurso transnacional, reflejo del contexto sociocultural en el que se desenvuelven los adolescentes.

La sexualidad es uno de los aspectos que ocupan a la mayor parte de las ficciones sobre y para adolescentes, un tema recurrente. El descubrimiento de la sexualidad, las relaciones entre parejas, las diferentes orientaciones sexuales...sirven como marcos referenciales para las tramas que abordan las teen series. Y en este campo concreto se centra el artículo de Vázquez, García-Ramos y Zurian «La representación de identidades queer adolescentes en Sex Education", prestando especial interés en el colectivo LGBTiQ+, y profundizando en la construcción de personajes cuya orientación sexual 
se sitúa dentro de la identidad queer para analizar el trato de la homofobia, la discriminación y la violencia que sufren las personas LGBTIQ+ en la serie analizada.

Desde el ámbito de la educomunicación se presenta el estudio de caso de una serie que tiene la particularidad de que ha sido creada a partir del trabajo de fin de grado de unas alumnas de la Universidad Pompeu Fabra. Se trata de Las del hockey emitida por TV3. En este análisis, realizado por Gil-Quintana y Gil-Tévar, se pone de manifiesto necesidad de generar una coeducación mediática que faculte el proceso de generar un pensamiento crítico, en este caso, sobre las representaciones de género discriminatorias basadas en la desigualdad sobre la construcción de identidades en la sociedad. Como afirman los autores, "la influencia de los medios y su proyección a través de las series ponen en relevancia la necesidad de una alfabetización mediática que proporcione una mirada coeducativa».

La música es otro componente muy presente en la vida de los adolescentes y, por ende, en la ficción televisiva. Este aspecto es reconocido por los creadores de series dirigidas a este tipo de público que prestan especial atención a los recursos musicales que aparecen en las mismas. Es el caso de Stranger Things, donde la utilización de la música diegética y extradiegética es fundamental para ubicar la serie en unas dimensiones espaciotemporales y, además, sirve como identificación de los personajes principales. En el trabajo de Alaminos Fernández, "La caracterización musical transmedia de las identidades juveniles: el caso de la serie Stranger Things" se realiza una comparativa entre las peculiaridades de los personajes y las playlists que se diseñaron en Spotify por los creadores de la serie, de tal forma que cada personaje tenía atribuidas canciones cercanas a sus gustos musicales, generando de ese modo una conexión emocional con el público potencial de la serie.

La narrativa audiovisual tiene un peso específico en el artículo de Sánchez López "Cómo salvar el mundo intentando no llegar tarde a clase: el viaje del héroe adolescente en las series Runaways y Capa y Puñal, en el que se ahonda en los tropos narrativos que comparten las historias de descubrimiento adolescente y los relatos serializados protagonizados por superhéroes. Si las historias centradas en héroes son, por derecho propio, parte del mainstream cinematográfico, esta investigación muestra cómo esa prevalencia en el cine todavía no ha sido alcanzada en un medio, la televisión, que permite a creadores y guionistas jugar con más libertad dentro de los condicionantes del género superheroico y mezclarlo con el rico tapiz de las historias centradas en jóvenes y adolescentes.

Por último, se presenta un estudio comparativo entre Gossip Girl, Pretty Little Liars y Get Even, en el que Morejón LLamas se centra en el análisis de los estereotipos de género y su relación con el ciberbulling, una de las grandes lacras de la sociedad sobre todo entre jóvenes y adolescentes y, en el que se plantea que las teen series tienen un papel relevante como agentes socializadores, ya que logran configurar una construcción identitaria entre su público potencial. En las series analizadas, sin embargo, se muestran unos mensajes muy lejanos a lo que cabría esperar si se considera que pueden influir en la audiencia. Desde la toxicidad en el amor a la mercantilización del sexo, pasando por la dulcificación de la violencia sexual, la banalización de la muerte o rasgos caracterizados en la mujer como el culto a la belleza y la estética o la tiranía de la moda. También se analiza el cambio de roles adulto/adolescente, su posición de estatus/consumismo, la soledad e incomprensión que sufren o la presión familiar y social a la que se enfrentan día a día. 
En definitiva, se presenta un monográfico donde se muestra una representación de algunas (dado el límite de espacio) posibilidades investigadoras que ofrecen las series de adolescentes para su estudio. El recorrido realizado por las teen series que aquí se presenta introduce variadas consideraciones desde diversas perspectivas y enfoques, y aunque, evidentemente, no agotan un objeto tan amplio, proporcionan diferentes acercamientos y formas de abordar un fenómeno apasionante al que, creemos, aún le queda mucho trayecto académico.

\section{Bibliografía}

Cascajosa, C. (2009). La nueva edad dorada de la televisión americana, Secuencias. Revista de historia del cine, n. 29, 2009, pp. 7-31.

Galán, E. (2006). Personajes, estereotipos y representaciones sociales. Una propuesta de estudio y análisis de la ficción televisiva. Revista ECO-PÓs, 9(1), 58-81. Recuperado de: https://earchivo.uc3m.es/handle/10016/9475

Raya-Bravo, I., Sánchez-Labella, I., \& Durán, V. (2018). La construcción de los personajes protagonistas en las series de Netflix: el perfil del adolescente en 13 Reasons Why y en Atypical. Comunicación y Medios, 27(37), 131-143. Doi:10.5354/0719-1529.2018.48631

Ross, S. M. \& Stein, L. E. (eds.) (2008). Teen Television: essays on programming and fandom. Jefferson: McFarland \& Company Publishers. 